\title{
Analytical Investigation of the Vibrational and Dynamic Response of Nano-Composite Cylindrical Shell Under Thermal Shock and Mild Heat Field by DQM Method
}

\author{
Masoud Rahmani*, Amin Moslemi Petrudi \\ Department of Mechanical Engineering, Tehran University, Iran \\ * Corresponding author email: Masoud.rahmani71@gmail.com \\ Received: 31 January 2020 / Revised: 19 March 2020 / Accepted: 21 March 2020 / Published: 25 March 2020
}

\begin{abstract}
In this paper, the vibrations and dynamic response of an orthotropic thin-walled composite cylindrical shell with epoxy graphite layers reinforced with carbon nanotubes under heat shock and heat field loading are investigated. the carbon nanotubes were uniformly distributed along the thickness of the composite layer. The problem is that at first there is a temperature change due to the thermal field in the cylinder and the cylinder is coincident with the thermal field, then the surface temperature of the cylinder rises abruptly. Partial derivative equations of motion are coupled to heat equations. The differential quadrature method (DQM) is used to solve the equations. In this study, the effects of length, temperature, thickness and radius parameters on the natural frequencies and mid-layer displacement are investigated. The results show that increasing the outside temperature reduces the natural frequency and increases the displacement of the system. Radial displacement results were also compared with previous studies and were found to be in good agreement with previous literature. Increasing the percentage of carbon nanotubes also increased the natural frequency of the system and decreased the mobility of the middle layer.
\end{abstract}

Keywords: Heat shock, DQM, natural frequency, composite, carbon nanotubes

\section{Introduction}

Increasing demand for improved product performance comes in many forms, including lower weight, higher rigidity and lower costs. the persistence of these demands has made current materials not respond to these up-to-date needs. So material scientists are always working to either improve the properties of existing materials or produce new materials, for example, new composites that have this property are among the investigated objects. One of the structures used widely in various industries is cylindrical shells. In this paper, the vibrational Response of composite cylindrical shell reinforced with carbon nanotubes under thermal shock load is investigated by DQM method. This loading occurs in many cases on structures, including rocket launchers, turbine suddenly stops(trip), space equipment, etc. Changes in temperature make two important effects. First, the amount of material is expanded when the temperature rises and contracted when cools. This expansion and contraction are usually proportional to the temperature variation. The thermal expansion coefficient $\alpha$ is a constant correlation between thermal strain and temperature variation relative to a reference temperature. In which there is no strain or thermal stress. The second effect relates to the stiffness and strength of the material; many materials become softer, more flexible and weaker when heated. Unwanted vibrations in systems result in poor performance, system life, or major failures and system disruptions, resulting in huge economic losses. Therefore, initial studies to control the vibrations of any system can prevent the occurrence of vibration problems when using the system. In this study, the dynamic response and the frequency response of composite cylindrical shells under thermal shock and a mild initial thermal field are Studied. One of the first studies in this field is the McQuillen, E.J. and Brull [1] paper, by numerical studies They checked the thermoelastic coupling of a thin cylindrical shell by using the traditional Gallerican method. In that study, they considered a nonlinear 
distribution of temperature in the shell thickness, and found that the difference between the coupling and non-coupling was about $1 \%$. The coupled thermoelasticity of shells of revolution was studied by Eslami et al. [2-4], based on second-order shell theory, and the governing equations including normal stress and strain as well as the transverse shear and rotary inertia were considered. Coupled dynamic thermoelastic equations of cylindrical thin shells were solved by Hakimelahi and Soltani [5] who used the numerical Galerkin method. They assumed variable mechanical and thermal shocks along the cylindrical shell with axial displacement and parabolic temperature distribution through thickness. Dynamic equilibrium equations of conical shells were obtained by Eslami and Moosavi [6] using a general linear theory which includes normal and lateral shear stresses and assuming dependency of strain field on temperature. Thus, semicoupled dynamic equations of conical shells were derived and solved by using the Galerkin finite element method. Tarn [7] examined the exact solution of thermal and thermal loads on a FGM cylinder. In his research, he considered the Yang model as a function of radius. In this study, a precise solution is presented for temperature distribution, thermoelastic deformation and stress field for a non-homogeneous thick cylinder. Alibeigloo [8] studied the thermoesthetic problem of static deformations in piezoelectric coated cylindrical shells. He used Navier's and state space methods to solve ordinary differential equations and the governing equations. R. Ansari,and J. Torabi [9] Free vibrations of cylindrical shells made of functional reinforced composites with carbon nanotubes under thermal loading and enclosed by elastic substrates have been investigated. They have affected the various parameters such as thermal loading, different boundary conditions, elastic bedding and geometric conditions Different on the natural frequency of the structure. Alibeigloo [10] studied the Elasticity solution of functionally graded carbon nanotube-reinforced. Wang et al [11] studied the axisymmetric thermoelastic interactionin a functionally graded thick hollow cylinder by an asymptotic approach. H. R. Esmaeili et al. [12] investigated Large amplitude thermally caused vibrations of cylindrical shells made of a through-the-thickness FGM. All of the thermo-mechanical properties of the FGM shell are considered to be functions of temperature and thickness coordinate. A. Keibolahi et al. [13] studied the dynamic buckling of a shallow arch subjected to a transient type of thermal loading by following the Budiansky-Hutchinson criterion. M. Javani et al. [14] analyzed nonlinear vibrations of the FGM shallow arches subjected to different sudden thermal loads Based on the uncoupled thermoelasticity assumptions. The heat equations solved numerically by a hybrid iterative GDQ method and Crank-Nicolson time marching scheme. M. Javani et al. [15] investigated large amplitude thermally induced vibrations of an annular FGM plate subjected to rapid surface heating. S.A.Mousavi et al [16] studied the dynamic response of the orthotropic composite shell under a mild heat field by undergoing a heat shock.

\section{Problem Formulation}

Properties of composite material reinforced by carbon nanotube are obtained using the following relationship [17]:

$$
\begin{aligned}
& E_{11_{C}}=\eta_{1} V_{C N T} E_{11}^{C N T}+V_{m} E^{m} \\
& \frac{\eta_{2}}{E_{22_{C}}}=\frac{V_{C N T}}{E_{22}^{C N T}}+\frac{V_{m}}{E_{m}} \\
& \frac{\eta_{3}}{G_{12_{C}}}=\frac{V_{C N T}}{G_{12}^{C N T}}+\frac{V_{m}}{G^{m}} \\
& v_{12_{C}}=V_{C N T} v_{12}^{C N T}+V_{m} \nu^{m} \\
& \rho_{0 C}=V_{C N T} \rho_{0}^{C N T}+V_{m} \rho_{0}^{m} \\
& \alpha_{11_{C}}=V_{C N T} \alpha_{11}^{C N T}+V_{m} \alpha^{m} \\
& \alpha_{22_{C}}=\left(1+v_{12}^{C N T}\right) V_{C N T} \alpha_{22}^{C N T}+\left(1+v^{m}\right) V_{m} \alpha^{m}-v_{12} \alpha_{11_{C}}
\end{aligned}
$$

In this relationship $E_{11}^{C N T}$ and $E_{22}^{C N T}$ are elastic modulus and $G_{12}^{C N T}$ shear modulus of single-walled carbon nanotubes. $\eta_{1}, \eta_{2}$ and $\eta_{3}$ are the carbon nanotube performance parameters. $V_{C N T}$ and $V_{m}$, respectively, are the volume fraction of carbon nanotubes and matrices that apply to the $\mathrm{V}_{\mathrm{CNT}}+\mathrm{V}_{\mathrm{m}}=1$ 
Rahmani et al., J. Mod. Sim. Mater.; Vol. 3 Issue 1, pp: 22-36, 2020

relation. $v_{12}^{C N T}$ and $\rho_{0}^{C N T}$ are Poisson's ratio and density of carbon nanotubes $\nu^{m}$ and $\rho_{0}^{m}$ are Poisson's ratio and density of matrix. In these relationships, $\alpha_{11}^{C N T}, \alpha_{22}^{C N T}$ and $\alpha^{\mathrm{m}}$ are the thermal expansion coefficients of the carbon nanotube and the matrix.

Consider a thin cylindrical shell of thickness $h$ and an average radius $R$ in the coordinates $(x, \Theta, z)$, as shown in figure 1, which $\mathrm{z}$ is measured from the midpoint of the cylinder, it is assumed that this The shell is on a uniform thermal field, with which it reaches the thermal equilibrium and suddenly it enters a thermal shock (this shock can be a sudden increase in temperature at either one of the internal or external surfaces, or both), The shell is isolated on its edges and the boundary conditions are considered to be clamped.
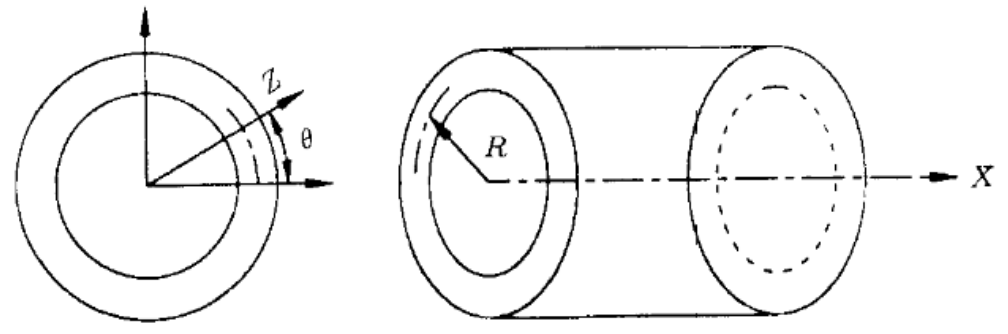

Fig. 1: Nano-Composite Cylindrical shell coordinates

In order to obtain the governing equations, a relatively thin cylindrical shell is assumed to be hypothesized. The displacement components are based on the first order approximation of the shells as follows [18]:

$$
\begin{aligned}
& U(x, \theta, z)=u_{0}(x, \theta)+z \Psi_{x}(x, \theta) \\
& V(x, \theta, z)=v_{0}(x, \theta)+z \Psi_{\theta}(x, \theta) \\
& W(x, \theta, z)=w_{0}(x, \theta)
\end{aligned}
$$

In these relations, $\mathrm{u}_{0}, \mathrm{v}_{0}$ and $\mathrm{w}_{0}$ represent the components of displacement vector of the point on the middle of the crust, and $\Psi_{\mathrm{x}}$ and $\Psi_{\Theta}$ represent the rotation of the tangents of the middle surface along the $\mathrm{x}$ and $\Theta$ axes, respectively. Therefore, in the hypothesized theory is just the normal strain $\varepsilon_{z}=0$, the components of other normal and shear strains at each point of the cylindrical thickness are obtained as follows [19]:

$$
\begin{array}{ll}
\varepsilon_{x}=\frac{\partial u}{\partial x} & \varepsilon_{\theta}=\frac{1}{R}\left(\frac{\partial v}{\partial x}+w\right) \\
\varepsilon_{x z}=\frac{\partial w}{\partial x}+\Psi_{x} & k_{x}=\frac{\partial \Psi_{x}}{\partial x} \\
k_{x \theta}=\frac{1}{R} \frac{\partial \Psi_{x}}{\partial \theta}+\frac{\partial \Psi_{\theta}}{\partial x}+\frac{1}{2 R}\left(\frac{\partial v}{\partial x}+\frac{1}{R} \frac{\partial u}{\partial \theta}\right) & \\
\varepsilon_{x \theta}=\frac{\partial v}{\partial x}+\frac{1}{R} \frac{\partial U}{\partial \theta} & k_{\theta}=\frac{1}{R} \frac{\partial \Psi_{\theta}}{\partial \theta} \\
\varepsilon_{\theta \mathrm{Z}}=\frac{1}{\mathrm{R}} \frac{\partial \mathrm{w}}{\partial \mathrm{x}}-\frac{\mathrm{v}}{\mathrm{R}}+\Psi_{\theta} & \\
\hline
\end{array}
$$

Due to the axial symmetry of geometry and loading, $(\partial / \partial \theta=0)$, the number of motion equations for dynamic cylindrical shell behavior is reduced in the general case of sanders theory and equations 2 and 5 are self-sufficient [20]. The motion equations in this case will be as follows:

$$
\begin{aligned}
& A_{11} \frac{\partial^{2} \mathrm{u}}{\partial \mathrm{x}^{2}}+\frac{A_{12}}{R} \frac{\partial w}{\partial x}+B_{11} \frac{\partial^{2} \Psi_{x}}{\partial x^{2}}-a t_{1}^{2} \frac{\partial T_{0}}{\partial x}-b t_{1}^{2} \frac{\partial T_{1}}{\partial x}=I_{1} \frac{\partial^{2} \mathrm{u}}{\partial \mathrm{t}^{2}}+\frac{1}{R} \frac{\partial^{2} \Psi_{x}}{\partial \mathrm{t}^{2}} \\
& \mathrm{~A}_{55} \frac{\partial^{2} \mathrm{w}}{\partial \mathrm{x}^{2}}+\mathrm{A}_{55} \frac{\partial \Psi_{\mathrm{x}}}{\partial \mathrm{x}}-\frac{1}{\mathrm{R}}\left(\mathrm{A}_{12} \frac{\partial \mathrm{u}}{\partial \mathrm{x}}+\mathrm{A}_{22} \frac{\mathrm{w}}{\mathrm{R}}+\mathrm{B}_{12} \frac{\partial \Psi_{\mathrm{x}}}{\partial \mathrm{x}}-\left(-\mathrm{at}_{2}^{4} \mathrm{~T}_{0}+\mathrm{bt}_{2}^{4} \mathrm{~T}_{1}\right)\right)=\mathrm{I}_{1} \frac{\partial^{2} \mathrm{w}}{\partial \mathrm{t}^{2}}
\end{aligned}
$$




$$
B_{11} \frac{\partial^{2} u}{\partial x^{2}}+\frac{B_{12}}{R} \frac{\partial w}{\partial x}+D_{11} \frac{\partial^{2} \Psi_{x}}{\partial x^{2}}-b t_{1}^{2} \frac{\partial T_{0}}{\partial x}-c t_{1}^{2} \frac{\partial T_{1}}{\partial x}-A_{55} \frac{\partial w}{\partial x}-A_{55} \Psi_{x}=\frac{I_{2}}{R} \frac{\partial^{2} u}{\partial t^{2}}+I_{3} \frac{\partial^{2} \Psi_{x}}{\partial t^{2}}
$$

To solve thermoelastic coupling problems, it is necessary to solve simultaneously the equations of motion and energy equations.

$$
\begin{aligned}
& k_{i j} T_{i j}-\left[c_{v} \rho \dot{T}+T_{a} \beta_{i j} o_{i j}\right]=0 \\
& \mathrm{~T}(\mathrm{x}, \theta, \mathrm{z}, \mathrm{t})=\mathrm{T}_{0}(\mathrm{x}, \theta, \mathrm{t})+\mathrm{zT}_{1}(\mathrm{x}, \theta, \mathrm{t})
\end{aligned}
$$

$\mathrm{T}_{1}$ and $\mathrm{T}_{0}$ are functions that we must obtain from the equation system. The Galerkin method is used to obtain two non-dependent thermal conductivity equations of equation (10). by averaging it in the thickness $\mathrm{z}$ of the shell, assuming a linear distribution in the thickness of the shell given by equation 35 , the two variables $T_{1}$ and $T_{0}$ appear in the energy equations. For a multilayer cylindrical shell under thermal shock with axial symmetry and a uniform distribution along $\mathrm{x}$, the energy equation 8 in terms of displacement terms is summarized as follows [21]:

$$
\text { Residual }=\rho c \dot{T}+T_{a}\left[\beta_{x x} \dot{U}_{, x}+\frac{\beta_{\theta \theta}}{R+z} \dot{\mathrm{W}}+\beta_{z z} \dot{\mathrm{W}}_{, z}+\beta_{x \theta} \dot{\mathrm{V}}_{, \mathrm{x}}\right]-\mathrm{k}_{\mathrm{xx}} \frac{\partial^{2} \mathrm{~T}}{\partial \mathrm{x}^{2}}-\mathrm{k}_{\mathrm{zz}}\left(\frac{\partial^{2} \mathrm{~T}}{\partial \mathrm{z}^{2}}+\frac{1}{\mathrm{R}+\mathrm{z}} \frac{\partial \mathrm{T}}{\partial \mathrm{z}}\right)
$$

The two integrals (11) and (12) yield two non-dependent energy equations, using two non-dependent T1 and T0 functions:

$$
\begin{aligned}
& \int_{z}(\text { Residual }) .(1) \cdot d z=0 \\
& \mathrm{R}_{\mathrm{c}}^{(1)} \dot{\mathrm{T}}_{0}+\mathrm{R}_{\mathrm{c}}^{(2)} \dot{\mathrm{T}}_{1}+\mathrm{R}_{\mathrm{x}}^{(1)} \dot{\mathrm{u}}_{0, \mathrm{x}}+\mathrm{R}_{\mathrm{x}}^{(2)} \dot{\Psi}_{\mathrm{x}, \mathrm{x}}+\mathrm{R}_{\theta \mathrm{x}}^{(1)} \dot{\Psi}_{\theta, \mathrm{x}}+\mathrm{R}_{\theta \mathrm{x}}^{(1)} \dot{\mathrm{v}}_{0, \mathrm{x}}+\mathrm{R}_{\mathrm{z}}^{(2)} \dot{\Psi}_{\mathrm{z}}+\mathrm{R}_{\mathrm{x}}^{(2)} \dot{\varphi}_{\mathrm{z}}+\frac{1}{\mathrm{R}} \mathrm{R}_{\theta}^{(1)} \dot{\mathrm{w}}_{0}+ \\
& \frac{1}{\mathrm{R}} \mathrm{R}_{\theta}^{(2)} \dot{\Psi}_{\mathrm{z}}+\frac{1}{2 \mathrm{R}} \mathrm{R}_{\theta}^{(3)} \dot{\varphi}_{\mathrm{z}}+\mathrm{R}_{\mathrm{kx}}^{(1)} \dot{\mathrm{T}}_{0, \mathrm{xx}}+\mathrm{R}_{\mathrm{kx}}^{(2)} \dot{\mathrm{T}}_{1, \mathrm{xx}}-\frac{1}{\mathrm{R}} \mathrm{R}_{\mathrm{kz}}^{(1)} \mathrm{T}_{1}-\left(\mathrm{h}_{\mathrm{i}}-\mathrm{h}_{\mathrm{o}}\right) \mathrm{T}_{0}+\mathrm{h}\left(\mathrm{h}_{\mathrm{i}}-\mathrm{h}_{\mathrm{o}}\right) \mathrm{T}_{1}+ \\
& {\left[\mathrm{h}_{\mathrm{i}} \mathrm{T}_{\mathrm{i}}(\mathrm{t})-\mathrm{h}_{0} \mathrm{~T}_{\infty}\right]=0}
\end{aligned}
$$

And

$$
\begin{aligned}
& \int_{z}(\text { Residual }) \cdot(z) \cdot d z=0 \\
& \mathrm{R}_{\mathrm{c}}^{(2)} \dot{\mathrm{T}}_{0}+\mathrm{R}_{\mathrm{c}}^{(3)} \dot{\mathrm{T}}_{1}+\mathrm{R}_{\mathrm{x}}^{(2)} \dot{\mathrm{u}}_{0, \mathrm{x}}+\mathrm{R}_{\mathrm{x}}^{(3)} \dot{\Psi}_{\mathrm{x}, \mathrm{x}}+\mathrm{R}_{\theta \mathrm{x}}^{(2)} \dot{\Psi}_{\theta, \mathrm{x}}+\mathrm{R}_{\theta \mathrm{x}}^{(2)} \dot{\mathrm{v}}_{0, \mathrm{x}}+\mathrm{R}_{\mathrm{z}}^{(3)} \dot{\Psi}_{\mathrm{z}}+\mathrm{R}_{\mathrm{x}}^{(3)} \dot{\varphi}_{\mathrm{z}}+\frac{1}{\mathrm{R}} \mathrm{R}_{\theta}^{(2)} \dot{\mathrm{w}}_{0}+ \\
& \frac{1}{\mathrm{R}} \mathrm{R}_{\theta}^{(3)} \dot{\Psi}_{\mathrm{z}}+\frac{1}{2 \mathrm{R}} \mathrm{R}_{\theta}^{(4)} \dot{\varphi}_{\mathrm{z}}+\mathrm{R}_{\mathrm{kx}}^{(2)} \dot{\mathrm{T}}_{0, \mathrm{xx}}+\mathrm{R}_{\mathrm{kx}}^{(3)} \dot{\mathrm{T}}_{1, \mathrm{xx}}-\frac{1}{\mathrm{R}} \mathrm{R}_{\mathrm{kz}}^{(2)} \mathrm{T}_{1}-\mathrm{h}\left[\left(\mathrm{h}_{\mathrm{i}}-\mathrm{h}_{\mathrm{o}}\right) \mathrm{T}_{0}-\left(\mathrm{h}_{\mathrm{i}}-\mathrm{h}_{\mathrm{o}}\right) \mathrm{T}_{1}-\right. \\
& \left.\left(\mathrm{h}_{\mathrm{i}} \mathrm{T}_{\mathrm{i}}(\mathrm{t})-\mathrm{h}_{0} \mathrm{~T}_{\infty}\right)\right]=0
\end{aligned}
$$

In these equations, some of the parameters are eliminated due to the axial symmetry $(\partial) / \partial \theta=0$. Relationships for the coefficients $\mathrm{R}_{j}^{(\mathrm{k})}$ are given in the appendix. As already mentioned, $\beta$ is the volumetric expansion coefficient and $\mathrm{k}$ is the conduction coefficients in different directions of the composite. To solve the problem, we need to solve a device that contains the equations of motion and energy equations. These equations are in the partial derivative (pde), that is, the function $\mathrm{x}$ and $\mathrm{t}$. To solve the equations, we need to write them to the finite element matrix form $M \ddot{x}+C \dot{x}+K x=F$ Matrix form can be used in a variety of ways, including the Rang Kuta method. The steps in converting the pde equations into the matrix form of 
Rahmani et al., J. Mod. Sim. Mater.; Vol. 3 Issue 1, pp: 22-36, 2020

the finite element are as follows. First, using the Galerkin method, we write the equations in a weak form, and then write them in a common matrix.

The initial conditions of the problem are considered zero:

$$
\begin{aligned}
& u_{0}(x, 0)=w_{0}(x, 0)=\Psi_{x 0}(x, 0)=0 \\
& \frac{\partial \mathrm{u}_{0}(\mathrm{x}, 0)}{\partial \mathrm{t}}=\frac{\partial \mathrm{w}_{0}(\mathrm{x}, 0)}{\partial \mathrm{t}}=\frac{\partial \Psi_{\mathrm{x} 0}(\mathrm{x}, 0)}{\partial \mathrm{t}}=0
\end{aligned}
$$

final form of the ode's equations is as follows:

$$
\begin{aligned}
& -\frac{A_{11}(m \pi)^{2}}{2 L} U_{m}+\frac{A_{12}(m \pi)}{2 R} W_{m}-\frac{B_{11}(m \pi)^{2}}{2 L} \Psi_{x}-a t_{1}^{2} \frac{(m \pi)}{2} T_{0 m}-b t_{1}^{2} \frac{(m \pi)}{2} T_{1 m} \\
& -\frac{\mathrm{LI}_{1}}{2} \ddot{\mathrm{U}}_{\mathrm{m}}(\mathrm{t})-\frac{\mathrm{LI}_{2}}{2} \ddot{\Psi}_{\mathrm{xm}}(\mathrm{t})= \\
& -\frac{\mathrm{RA}_{12}(\mathrm{~m} \pi)}{2} \mathrm{U}_{\mathrm{m}}+\frac{\mathrm{A}_{22} \mathrm{~L}}{2} \mathrm{~W}_{\mathrm{m}}-\frac{\mathrm{RA}_{55}(\mathrm{~m} \pi)}{2} \Psi_{\mathrm{xm}}-\frac{\mathrm{Rat}_{2}^{4} \mathrm{~L}}{2} \mathrm{~T}_{0 \mathrm{~m}}-\frac{\mathrm{Rbt}_{2}^{4} \mathrm{~L}}{2} \mathrm{~T}_{1 \mathrm{~m}} \\
& -\frac{\mathrm{A}_{55}(\mathrm{~m} \pi)^{2}}{2 \mathrm{~L}} \mathrm{~W}_{\mathrm{m}}-\frac{\mathrm{I}_{1} \mathrm{~L}}{2} \ddot{\mathrm{W}}=0 \\
& -\frac{\mathrm{B}_{11}(\mathrm{~m} \pi)^{2}}{2 \mathrm{~L}} U_{\mathrm{m}}-\frac{\mathrm{D}_{11}(\mathrm{~m} \pi)^{2}}{2 \mathrm{~L}} \Psi_{\mathrm{xm}}-\frac{\mathrm{A}_{55}(\mathrm{~m} \pi)}{2 \mathrm{R}} \mathrm{W}_{\mathrm{m}}-\frac{\mathrm{a}_{45} \mathrm{~L}}{2} \Psi_{\mathrm{xm}}-\frac{\mathrm{LI}_{2}}{2} \ddot{U}_{\mathrm{m}}-\frac{\mathrm{LI}_{3}}{2} \ddot{\Psi}_{\mathrm{m}} \\
& -\frac{\mathrm{bt}_{1}^{2}(\mathrm{~m} \pi)}{2} \mathrm{~T}_{0 \mathrm{~m}}-\frac{\mathrm{ct}_{1}^{2}(\mathrm{~m} \pi)}{2} \mathrm{~T}_{1 \mathrm{~m}}=0 \\
& \frac{\mathrm{R}_{\mathrm{c}}^{(1)} \mathrm{L}}{2} \dot{\mathrm{T}}_{0}+\frac{\mathrm{R}_{\mathrm{c}}^{(2)} \mathrm{L}}{2} \dot{\mathrm{T}}_{1}+\frac{\mathrm{R}_{\mathrm{x}}^{(1)}(\mathrm{m} \pi)}{2} \dot{\mathrm{u}}+\frac{\mathrm{R}_{\mathrm{x}}^{(2)}(\mathrm{m} \pi)}{2} \dot{\Psi}_{\mathrm{x}}+\frac{\mathrm{R}_{\Theta}^{(1)} \mathrm{L}}{2 \mathrm{R}} \dot{\mathrm{w}}_{0}-\frac{\mathrm{R}_{\mathrm{kx}}^{(1)}(\mathrm{m} \pi)^{2}}{2 \mathrm{~L}} \mathrm{~T}_{0} \\
& -\frac{\mathrm{R}_{\mathrm{kx}}^{(2)}(\mathrm{m} \pi)^{2}}{2 \mathrm{~L}} \mathrm{~T}_{1}+\frac{\mathrm{R}_{\mathrm{kz}}^{(1)} \mathrm{L}}{2 \mathrm{R}} \mathrm{T}_{1}-\frac{\left(\mathrm{h}_{\mathrm{i}}-\mathrm{h}_{\mathrm{o}}\right) \mathrm{L}}{2} \mathrm{~T}_{0}+\frac{\left(\mathrm{h}_{\mathrm{i}}-\mathrm{h}_{\mathrm{o}}\right) \mathrm{hL}}{2} \mathrm{~T}_{1}-\left[\mathrm{h}_{\mathrm{i}} \mathrm{T}_{\mathrm{i}}(\mathrm{t})\right. \\
& \left.\left.-\mathrm{h}_{0} \mathrm{~T}_{\infty}\right] \frac{\mathrm{L}}{\mathrm{m} \pi} \cos \left(\frac{\mathrm{m} \pi}{\mathrm{L}} \mathrm{x}\right)\right]_{0}^{\mathrm{L}}=0 \\
& \frac{\mathrm{R}_{\mathrm{c}}^{(2)} \mathrm{L}}{2} \dot{\mathrm{T}}_{0}+\frac{\mathrm{R}_{\mathrm{c}}^{(3)} \mathrm{L}}{2} \dot{\mathrm{T}}_{1}+\frac{\mathrm{R}_{\mathrm{x}}^{(2)}(\mathrm{m} \pi)}{2} \dot{\mathrm{u}}+\frac{\mathrm{R}_{\mathrm{x}}^{(3)}(\mathrm{m} \pi)}{2} \dot{\Psi}_{\mathrm{x}}+\frac{\mathrm{R}_{\Theta}^{(2)} \mathrm{L}}{2 \mathrm{R}} \dot{\mathrm{w}}_{0}-\frac{\mathrm{R}_{\mathrm{kx}}^{(2)}(\mathrm{m} \pi)^{2}}{2 \mathrm{~L}} \mathrm{~T}_{0} \\
& -\frac{\mathrm{R}_{\mathrm{kx}}^{(3)}(\mathrm{m} \pi)^{2}}{2 \mathrm{~L}} \mathrm{~T}_{1}+\frac{\mathrm{R}_{\mathrm{kz}}^{(2)} \mathrm{L}}{2 \mathrm{R}} \mathrm{T}_{1}-\frac{\mathrm{h}\left(\mathrm{h}_{\mathrm{i}}-\mathrm{h}_{\mathrm{o}}\right) \mathrm{L}}{2} \mathrm{~T}_{0}+\frac{\left(\mathrm{h}_{\mathrm{i}}-\mathrm{h}_{\mathrm{o}}\right) \mathrm{hL}}{2} \mathrm{~T}_{1}+\left[\mathrm{h}_{\mathrm{i}} \mathrm{T}_{\mathrm{i}}(\mathrm{t})\right. \\
& \left.\left.-\mathrm{h}_{0} \mathrm{~T}_{\infty}\right] \frac{\mathrm{L}}{\mathrm{m} \pi} \cos \left(\frac{\mathrm{m} \pi}{\mathrm{L}} \mathrm{x}\right)\right]_{0}^{\mathrm{L}}=0
\end{aligned}
$$

Now, the equations can be written in the form of the matrix $M \ddot{x}+C \dot{x}+K x=F$, and this equation can be solved by different methods. In this study, the DQM methods has been used.

\section{Solution by DQM Method}

DQM is one of the numerical methods in which the weighted coefficients of the governing differential equations are converted into first-order algebraic equations. Thus, at each point, the derivative will be expressed as a linear sum of the weighting coefficients and the function values at that point and the other 
points in the domain and in the coordinate axis. In general, in these methods, the one-dimensional function derivative is defined as follows [22-23]:

$\left.\frac{d^{n} f}{d x^{n}}\right|_{x=x_{i}}=\sum_{j=1}^{N} C_{i j}^{(n)} f\left(x_{j}\right), n=1,2, \ldots, N-1$

Where the $f(x)$ is desired function $C_{i j}$ is derivative weights and $N$ is the number of grid points. The relation (22) is called the quadratic differential. Two important factors in this method are the selection of sample points and weighting coefficients.

\section{Select sample points}

There are several ways to select sample points. The simplest is the choice of dividing the domain into 6 points with equal distance that the experience shown will have no accurate answer. Using orthogonal polynomial roots is one of the common methods in selecting sample points with uneven distances. The roots of Chebysno polynomials are used extensively in engineering issues and produce good results. This distance is expressed as follows [24]:

$$
\begin{aligned}
& x_{i}=\frac{L}{2}\left[1-\cos \left(\frac{i-1}{N-1} \cdot \pi\right)\right], \quad i=1,2, \ldots, N \\
& y_{j}=\frac{W}{2}\left[1-\cos \left(\frac{j-1}{M-1} \cdot \pi\right)\right], \quad j=1,2, \ldots, M
\end{aligned}
$$

Various methods have been proposed to obtain the weighting coefficient matrix. In these methods, the function-function is assumed to be known. By deriving this function and satisfying the equality, you gain weight coefficients. This hypothetical function used to obtain weight coefficients is called the test function.in order to have no constraint on the number of grid points used for the approximation and the weighting coefficients, the Lagrange interpolated polynomials fi( $\mathrm{x})$ are expressed by:

$$
g(x)=\frac{L(x)}{\left(x-x_{i}\right) L_{1}\left(x_{i}\right)}, i=1,2, \ldots, N
$$

Where $L(x)=\prod_{j=1}^{N}\left(x-x_{j}\right)$,also $\mathrm{L}_{1}(\mathrm{x})$ is a derivative of Lagrange's orthogonal polynomial function of order $\mathrm{N}$ and is defined as $L\left(x_{i}\right)=\prod_{j=1}^{N}\left(x_{i}-x_{j}\right)$, By substituting Eq. in Eq one can find

$$
\begin{array}{ll}
C_{i j}^{(1)}=\frac{L_{1}\left(x_{i}\right)}{\left(x_{i}-x_{j}\right) L_{1}\left(x_{j}\right)} & \text { For } \mathrm{i} \neq \mathrm{j}, \mathrm{i}, \mathrm{j}=1,2, \ldots, \mathrm{N} \\
C_{i j}^{(1)}=-\sum_{j=1, j \neq i} C_{i j}^{1} & \text { For } \mathrm{i}=\mathrm{j}, \mathrm{i}, \mathrm{j}=1,2, \ldots, \mathrm{N}
\end{array}
$$

The vibration modes of composite circular cylindrical shells are characterized by $\mathrm{n}$, the number of circumferential waves and $m$, the number of axial waves. A general expression for the displacement components in any mode may be written in the following form:

$$
\begin{aligned}
& u(x . \theta . t)=U(x) \cos (n \theta) \sin (\omega t) \\
& v(x . \theta . t)=V(x) \sin (n \theta) \sin (\omega t) \\
& w(x . \theta . t)=W(x) \cos (n \theta) \sin (\omega t) \\
& \Psi_{x}(x . \theta . t)=\Psi_{x}(x) \cos (n \theta) \sin (\omega t) \\
& \Psi_{\theta}(x . \theta . t)=\Psi_{\theta}(x) \sin (n \theta) \sin (\omega t)
\end{aligned}
$$

By writing the equations of motion (17-21) by application of differential quadrature method (DQM) the following set of equations are obtained:

$$
\begin{gathered}
-\frac{\mathrm{A}_{11}(\mathrm{~m} \pi)^{2}}{2 \mathrm{~L}} \mathrm{U}_{\mathrm{m}}+\frac{\mathrm{A}_{12}(\mathrm{~m} \pi)}{2 \mathrm{R}} \mathrm{W}_{\mathrm{m}}-\frac{\mathrm{B}_{11}(\mathrm{~m} \pi)^{2}}{2 \mathrm{~L}} \Psi_{\mathrm{x}}-\mathrm{at}_{1}^{2} \frac{(\mathrm{m} \pi)}{2} \mathrm{~T}_{0 \mathrm{~m}}-\mathrm{bt}_{1}^{2} \frac{(\mathrm{m} \pi)}{2} \mathrm{~T}_{1 \mathrm{~m}} \\
-\frac{\mathrm{LI}_{1}}{2} \sum_{1}^{N} A_{i j}^{(2)} \mathrm{U}_{\mathrm{m}}(\mathrm{t})-\frac{\mathrm{LI}_{2}}{2} \sum_{1}^{N} A_{i j}^{(2)} \Psi_{x \mathrm{~m}}(\mathrm{t})=0
\end{gathered}
$$




$$
\begin{aligned}
-\frac{\mathrm{RA}_{12}(\mathrm{~m} \pi)}{2} \mathrm{U}_{\mathrm{m}} & +\frac{\mathrm{A}_{22} \mathrm{~L}}{2} \mathrm{~W}_{\mathrm{m}}-\frac{\mathrm{RA}_{55}(\mathrm{~m} \pi)}{2} \Psi_{\mathrm{xm}}-\frac{\mathrm{Rat}_{2}^{4} \mathrm{~L}}{2} \mathrm{~T}_{0 \mathrm{~m}}-\frac{\mathrm{Rbt}_{2}^{4} \mathrm{~L}}{2} \mathrm{~T}_{1 \mathrm{~m}}-\frac{\mathrm{A}_{55}(\mathrm{~m} \pi)^{2}}{2 \mathrm{~L}} \mathrm{~W}_{\mathrm{m}} \\
- & \frac{\mathrm{I}_{1} \mathrm{~L}}{2} \sum_{1}^{N} A_{i j}^{(2)} \mathrm{W}=0
\end{aligned}
$$

$$
\begin{aligned}
-\frac{\mathrm{B}_{11}(\mathrm{~m} \pi)^{2}}{2 \mathrm{~L}} \mathrm{U}_{\mathrm{m}} & -\frac{\mathrm{D}_{11}(\mathrm{~m} \pi)^{2}}{2 \mathrm{~L}} \Psi_{\mathrm{xm}}-\frac{\mathrm{A}_{55}(\mathrm{~m} \pi)}{2 \mathrm{R}} \mathrm{W}_{\mathrm{m}}-\frac{\mathrm{a}_{45} \mathrm{~L}}{2} \Psi_{\mathrm{xm}}-\frac{\mathrm{LI}_{2}}{2} \sum_{1}^{N} A_{i j}^{(2)} \mathrm{U}_{\mathrm{m}} \\
- & \frac{\mathrm{LI}_{3}}{2} \sum_{1}^{N} A_{i j}^{(2)} \Psi_{\mathrm{m}}-\frac{\mathrm{bt}_{1}^{2}(\mathrm{~m} \pi)}{2} \mathrm{~T}_{0 \mathrm{~m}}-\frac{\mathrm{ct}_{1}^{2}(\mathrm{~m} \pi)}{2} \mathrm{~T}_{1 \mathrm{~m}}=0
\end{aligned}
$$

$$
\begin{aligned}
\frac{\mathrm{R}_{\mathrm{c}}^{(1)} \mathrm{L}}{2} \sum_{1}^{N} A_{i j}^{(1)} \mathrm{T}_{0} & +\frac{\mathrm{R}_{\mathrm{c}}^{(2)} \mathrm{L}}{2} \sum_{1}^{N} A_{i j}^{(1)} \mathrm{T}_{1}+\frac{\mathrm{R}_{\mathrm{x}}^{(1)}(\mathrm{m} \pi)}{2} \sum_{1}^{N} A_{i j}^{(1)} \mathrm{u}+\frac{\mathrm{R}_{\mathrm{x}}^{(2)}(\mathrm{m} \pi)}{2} \sum_{1}^{N} A_{i j}^{(1)} \Psi_{x} \\
+ & \frac{\mathrm{R}_{\theta}^{(1)} \mathrm{L}}{2 \mathrm{R}} \sum_{1}^{N} A_{i j}^{(1)} \mathrm{w}_{0}-\frac{\mathrm{R}_{\mathrm{kx}}^{(1)}(\mathrm{m} \pi)^{2}}{2 \mathrm{~L}} \mathrm{~T}_{0}-\frac{\mathrm{R}_{\mathrm{kx}}^{(2)}(\mathrm{m} \pi)^{2}}{2 \mathrm{~L}} \mathrm{~T}_{1}+\frac{\mathrm{R}_{\mathrm{kz}}^{(1)} \mathrm{L}_{1}}{2 \mathrm{R}} \mathrm{T}_{1} \\
& \left.-\frac{\left(\mathrm{h}_{\mathrm{i}}-\mathrm{h}_{\mathrm{o}}\right) \mathrm{L}}{2} \mathrm{~T}_{0}+\frac{\left(\mathrm{h}_{\mathrm{i}}-\mathrm{h}_{\mathrm{o}}\right) \mathrm{hL}}{2} \mathrm{~T}_{1}-\left[\mathrm{h}_{\mathrm{i}} \mathrm{T}_{\mathrm{i}}(\mathrm{t})-\mathrm{h}_{0} \mathrm{~T}_{\infty}\right] \frac{\mathrm{L}}{\mathrm{m} \pi} \cos \left(\frac{\mathrm{m} \pi}{\mathrm{L}} \mathrm{x}\right)\right]_{0}^{\mathrm{L}}=0
\end{aligned}
$$

$$
\begin{aligned}
\frac{\mathrm{R}_{\mathrm{c}}^{(2)} \mathrm{L}}{2} \sum_{1}^{N} A_{i j}^{(1)} T_{0} & +\frac{\mathrm{R}_{\mathrm{c}}^{(3)} \mathrm{L}}{2} \sum_{1}^{N} A_{i j}^{(1)} \mathrm{T}_{1}+\frac{\mathrm{R}_{\mathrm{x}}^{(2)}(\mathrm{m} \pi)}{2} \sum_{1}^{N} A_{i j}^{(1)} \mathrm{u}+\frac{\mathrm{R}_{\mathrm{x}}^{(3)}(\mathrm{m} \pi)}{2} \sum_{1}^{N} A_{i j}^{(1)} \Psi_{x} \\
& +\frac{\mathrm{R}_{\theta}^{(2)} \mathrm{L}}{2 \mathrm{R}} \sum_{1}^{N} A_{i j}^{(1)} \mathrm{w}_{0}-\frac{\mathrm{R}_{\mathrm{kx}}^{(2)}(\mathrm{m} \pi)^{2}}{2 \mathrm{~L}} \mathrm{~T}_{0}-\frac{\mathrm{R}_{\mathrm{kx}}^{(3)}(\mathrm{m} \pi)^{2}}{2 \mathrm{~L}} \mathrm{~T}_{1}+\frac{\mathrm{R}_{\mathrm{kz}}^{(2)} \mathrm{L}}{2 \mathrm{R}} \mathrm{T}_{1} \\
& \left.-\frac{\mathrm{h}\left(\mathrm{h}_{\mathrm{i}}-\mathrm{h}_{\mathrm{o}}\right) \mathrm{L}}{2} \mathrm{~T}_{0}+\frac{\left(\mathrm{h}_{\mathrm{i}}-\mathrm{h}_{\mathrm{o}}\right) \mathrm{hL}}{2} \mathrm{~T}_{1}+\left[\mathrm{h}_{\mathrm{i}} \mathrm{T}_{\mathrm{i}}(\mathrm{t})-\mathrm{h}_{0} \mathrm{~T}_{\infty}\right] \frac{\mathrm{L}}{\mathrm{m} \pi} \cos \left(\frac{\mathrm{m} \pi}{\mathrm{L}} \mathrm{x}\right)\right]_{0}^{\mathrm{L}}=0
\end{aligned}
$$

where $A_{\mathrm{ij}}$ represents the weighting coefficient of order $r$ corresponding to ith grid point.

The boundary conditions for a simply-supported shell are given as:

$\mathrm{u}=\mathrm{v}=\mathrm{w}=\mathrm{M}_{\mathrm{xx}}=\Psi_{\theta}=0$ at $\mathrm{x}=0$ and $\mathrm{x}=\mathrm{L}$

clamped-free circular cylindrical shell. The boundary conditions for this case are given as:

$\mathrm{u}=\mathrm{v}=\mathrm{w}=\Psi_{\mathrm{x}}=\Psi_{\theta}=0$ at $\mathrm{x}=0$

$\mathrm{u}=\mathrm{v}=\mathrm{w}=\mathrm{M}_{\mathrm{xx}}=\Psi_{\theta}=0 \quad$ at $\mathrm{x}=\mathrm{L}$

And for clamped-clamped boundary conditions:

$\mathrm{u}=\mathrm{v}=\mathrm{w}=\Psi_{\mathrm{x}}=\Psi_{\theta}=0 \quad$ at $\mathrm{x}=0$ and $\mathrm{x}=\mathrm{L}$

\section{Numerical Results and Discussion}

In this section of the work, the results of this study are compared with those of others published in prestigious journals. for this purpose, we compared the results of the radial motion of the intermediate layer with the results of the Jeng-Shian Chang et al [18], which can be seen in the figures 2-4 for the shells of different fiber angles. In all of these cases, the shell is considered as a double-headed. As you can see, the results are very close to the results of Chang et al [18] work. All results are obtained using the properties listed in the Table 1. Otherwise, the values that have been changed in the description of the image are listed. 


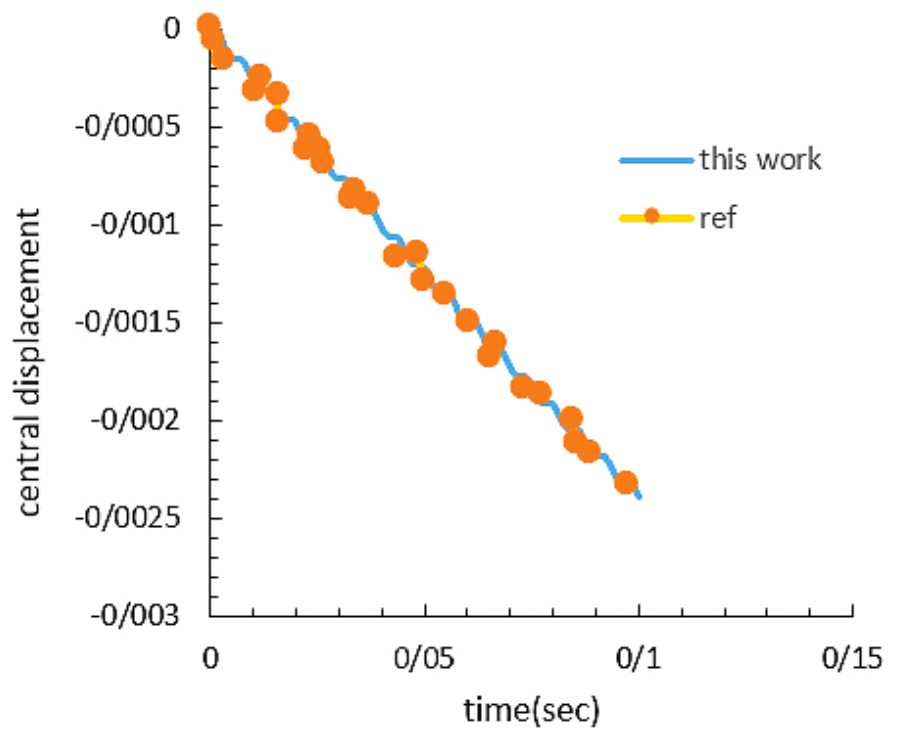

Fig. 2: Comparison of the interlayer displacement for the fiber angle $(45,-45,45,-45)$ with ref [6]

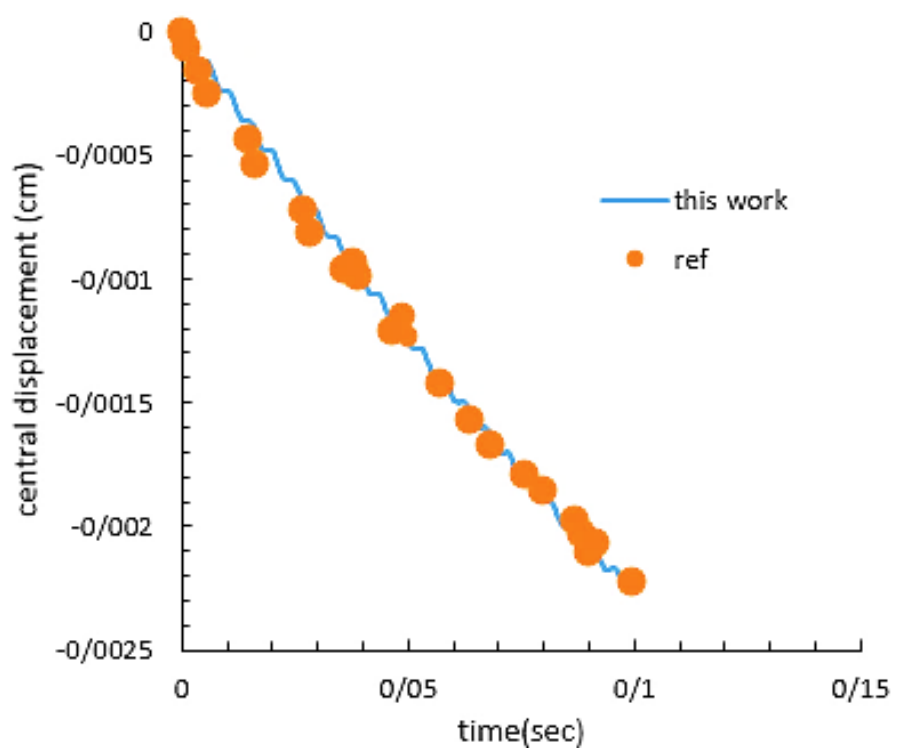

Fig. 3: Comparison of the interlayer displacement for the fiber angle $(0,90,0,90)$ with ref [6]

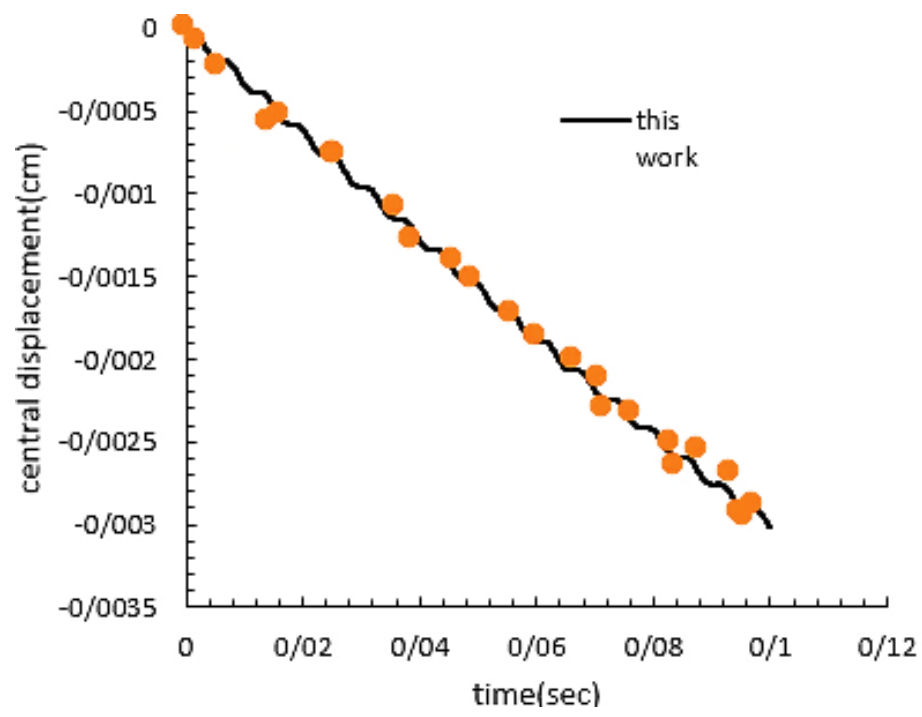

Fig. 4: Comparison of the interlayer displacement for the fiber angle $(0,0,0,0)$ with ref [6] 
Rahmani et al., J. Mod. Sim. Mater.; Vol. 3 Issue 1, pp: 22-36, 2020

Table 1: Geometry and material properties of composite shell

\begin{tabular}{ll}
\hline \multicolumn{1}{c}{ Parameter value } & \multicolumn{1}{c}{ Parameter } \\
\hline $25.4 \mathrm{~cm}$ & Cylindrical length $(\mathrm{L})$ \\
$50 \mathrm{~cm}$ & Middle layer radius $(\mathrm{R})$ \\
$0.0635 \mathrm{~cm}$ & Thickness of each layer $(\mathrm{H})$ \\
$(-45,45,-45,45)$ & Fiber angle \\
$137.9 \mathrm{Gpa}$ & Young's modulus for direction 1 (E11) \\
$8.96 \mathrm{Gpa}$ & Young's modulus for direction 2and3(E22=E33) \\
$7.1 \mathrm{Gpa}$ & Shear modulus) G12=G13( \\
$3.447 \mathrm{Gpa}$ & Shear modulus $(\mathrm{G} 23)$ \\
0.3 & Poisson's ratio $(\mathrm{v})$ \\
$46.2 \times 10^{-3} \mathrm{~J} / \mathrm{cm} \mathrm{s} \mathrm{K}$ & Heat transfer coefficient in direction 1 (K11) \\
$7.2 \times 10^{-3} \mathrm{~J} / \mathrm{cm} \mathrm{s} \mathrm{K}$ & Heat transfer coefficient in direction 2and3(K22=K33) \\
& \\
$16.35 \mathrm{~J} / \mathrm{cm}^{2} \mathrm{~s}$ & Thermal shock load(ft) \\
$100{ }^{\circ} \mathrm{C}$ & Initial temperature change $(\Delta \theta)$ \\
\hline \hline
\end{tabular}

The properties of carbon nanotubes are presented in Table 2 and the values of carbon nanotube performance parameters are presented in Table 3.

Table 2: Material properties of single-walled carbon nanotube $(10,10)\left(v_{12}^{C N T}=0.175\right)[17]$.

\begin{tabular}{cccc}
\hline Temperature $(\mathrm{K})$ & 700 & 500 & 300 \\
\hline$E_{11}^{C N T}(\mathrm{TPa})$ & 5.4744 & 5.5308 & 5.6466 \\
$E_{22}^{C N T}(\mathrm{TPa})$ & 6.8641 & 6.9348 & 7.0800 \\
$G_{12}^{C N T}(\mathrm{TPa})$ & 1.9644 & 1.9643 & 1.9445 \\
$\alpha_{11}^{C N T}\left(10^{-6} / \mathrm{K}\right)$ & 4.6677 & 4.5361 & 3.4584 \\
$\alpha_{2}^{C N T}\left(10^{-6} / \mathrm{K}\right)$ & 4.8943 & 8.0189 & 5.1682 \\
\hline
\end{tabular}

Table 3: Efficiency parameters for different values of VCNT [17].

\begin{tabular}{cccc}
\hline$\eta_{3}$ & $\eta_{2}$ & $\eta_{1}$ & $V_{\text {CNT }}$ \\
\hline 0.934 & 0.934 & 0.149 & 0.11 \\
0.941 & 0.941 & 0.150 & 0.14 \\
1.381 & 1.381 & 0.149 & 0.17 \\
\hline
\end{tabular}

The effect of change in shell thickness on the displacement of the middle layer and frequency is shown in Figures 5 and 6. 


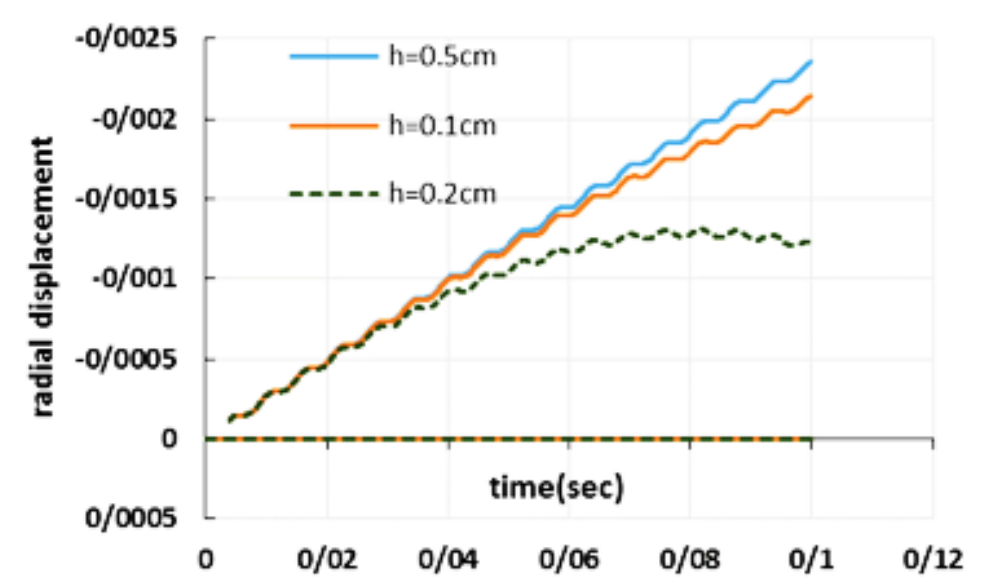

Fig.5: Changes in the radial displacement of the interlayer in different thicknesses of the layers

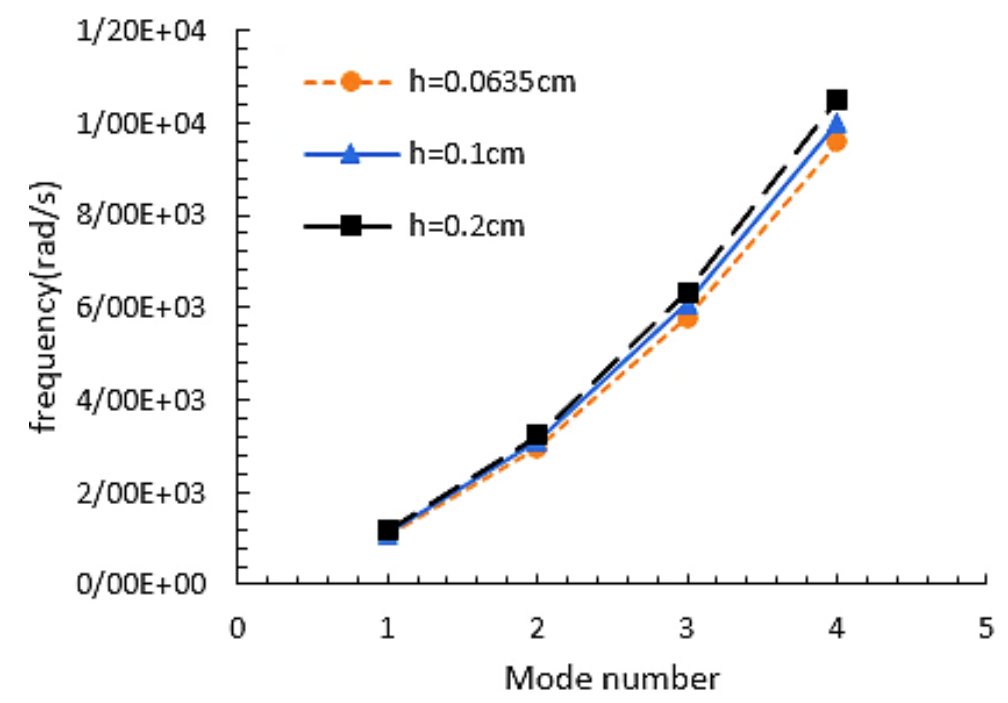

Fig. 6: Changes in natural frequencies by changing the thickness of the layers

In Figures 7 and 8, the length of the cylindrical length parameter is investigated. It is seen that in Figure 7, with increasing length of the cylinder, the displacement of the middle layer is increased, as can be seen in Figure 8 , by increasing the length of the cylinder The natural frequency has decreased.

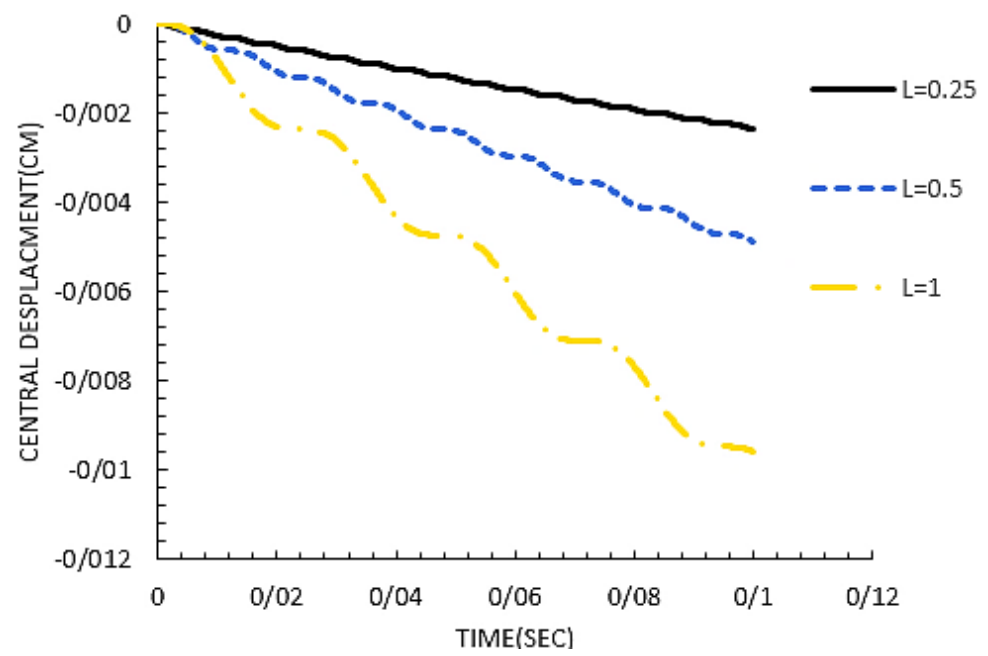

Fig. 7: Change in the radial displacement of the middle layer by changing the length of the cylinder 


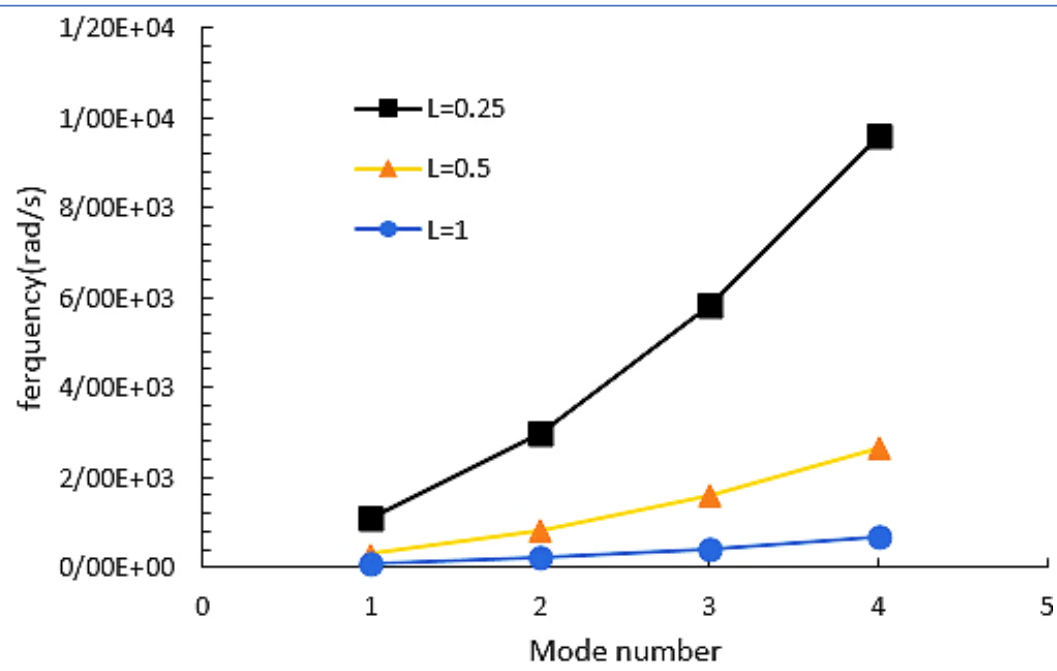

Fig. 8: Change in natural frequencies by changing the length of the cylinder

Another important geometric parameter in the cylindrical shell is the radius of the intermediate layer, which in Figures. 9 and 10, respectively, deals with the effects of the middle layer radius on the displacement of the middle layer and the frequency. By increasing the radius, the displacement Dropped. In Figure 10, it is also observed that the natural frequency increased by increasing the radius.

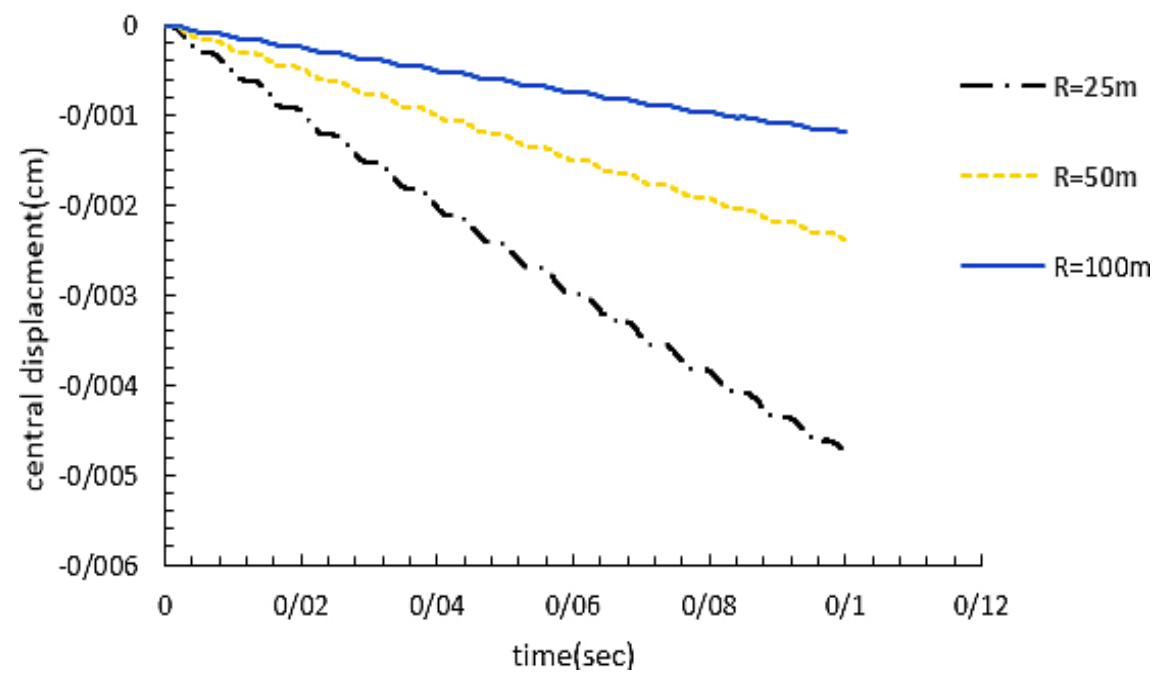

Fig. 9: Changes in the radial displacement of the intermediate layer by changing the radius of the cylinder

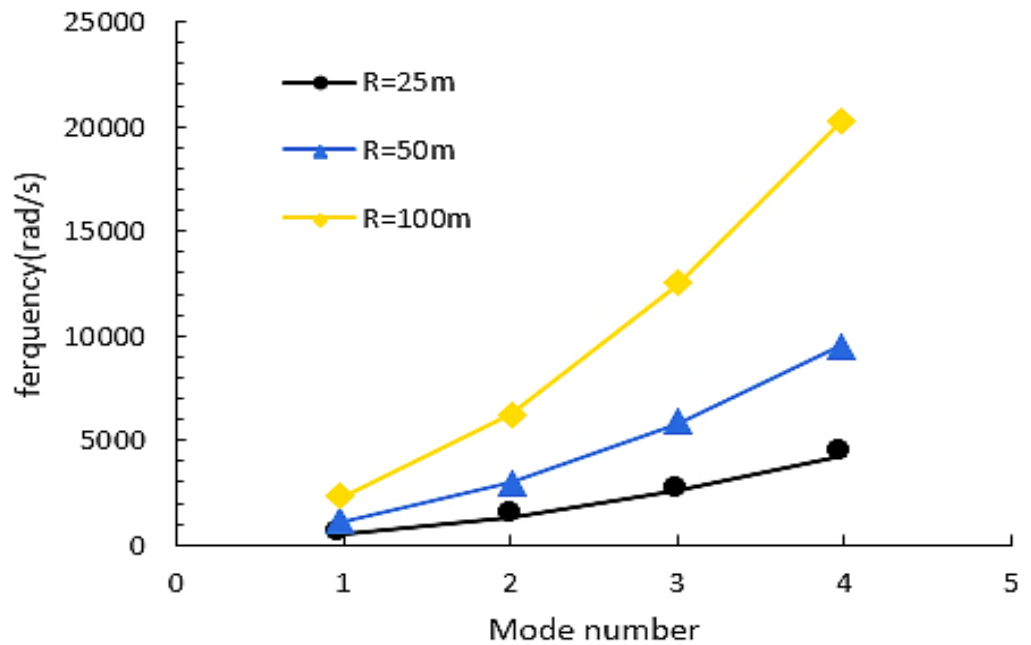

Fig. 10: Change in natural frequencies by changing the radius of the cylinder 
Analytical Investigation of the Vibrational and Dynamic Response of Nano-Composite Cylindrical Shell.............

In the next study, Figure 11 shows the effect of different angles of the fiber in the dynamic response.

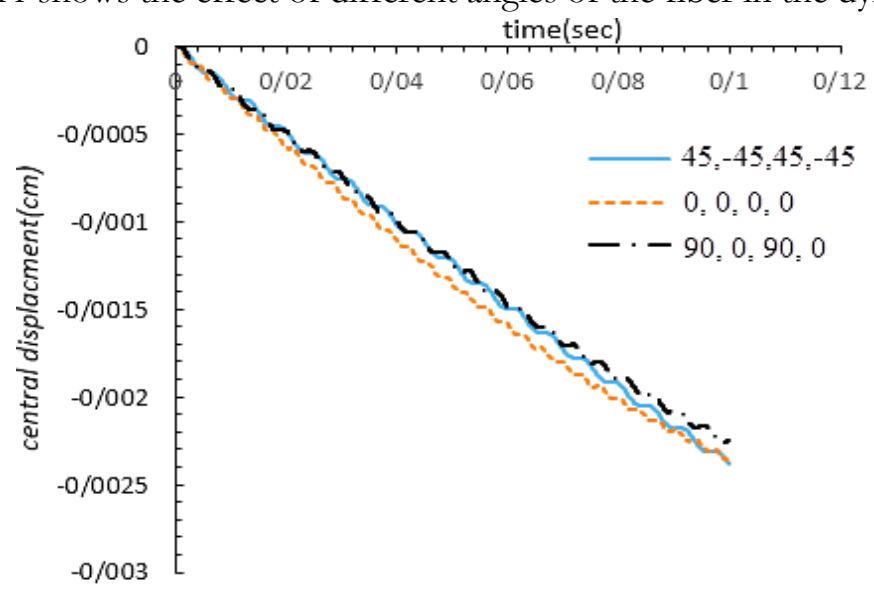

Fig. 11: Changes in the radial displacement of the intermediate layer by changing the Fiber angle The basic parameter to be considered in this study is the effect of the shock load ( $\mathrm{ft}$ ) on the range of vibration displacement. The result of this study is shown in Figure 12.

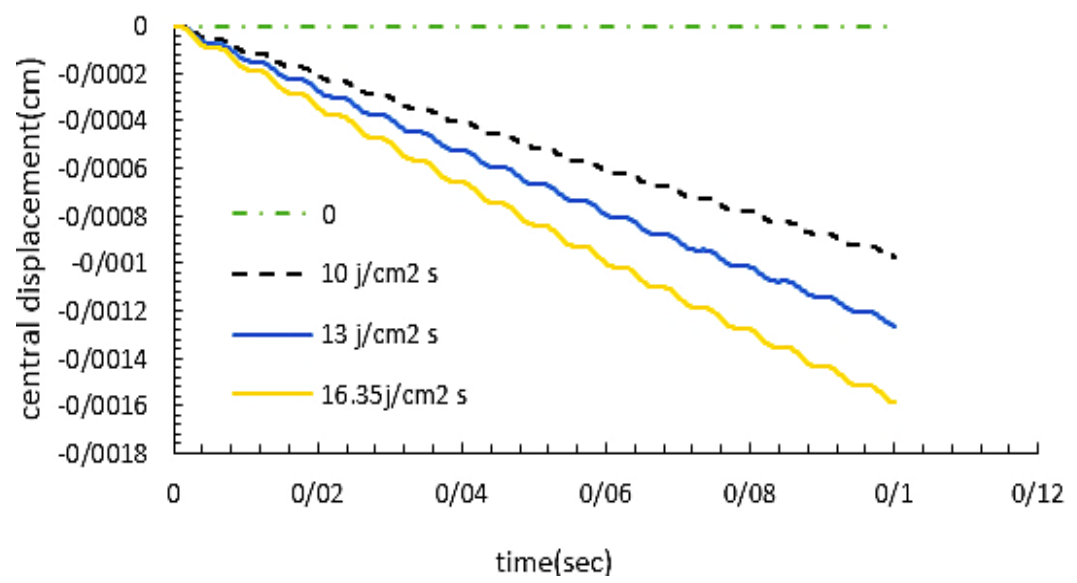

Fig. 12: Changes in the radial displacement of the intermediate layer with a change in thermal shock Figures 13 and 14 show a change in the natural frequency and displacement of the middle layer by changing the thermal field temperature. As the temperature rises, the material becomes softer so that the displacement rises, but due to the initial stresses it causes that the natural frequency decreases. Figure 13 shows that the field does not have much effect on the fundamental frequency (first frequency), but the increase of the field affects the subsequent frequencies and reduces the frequency.

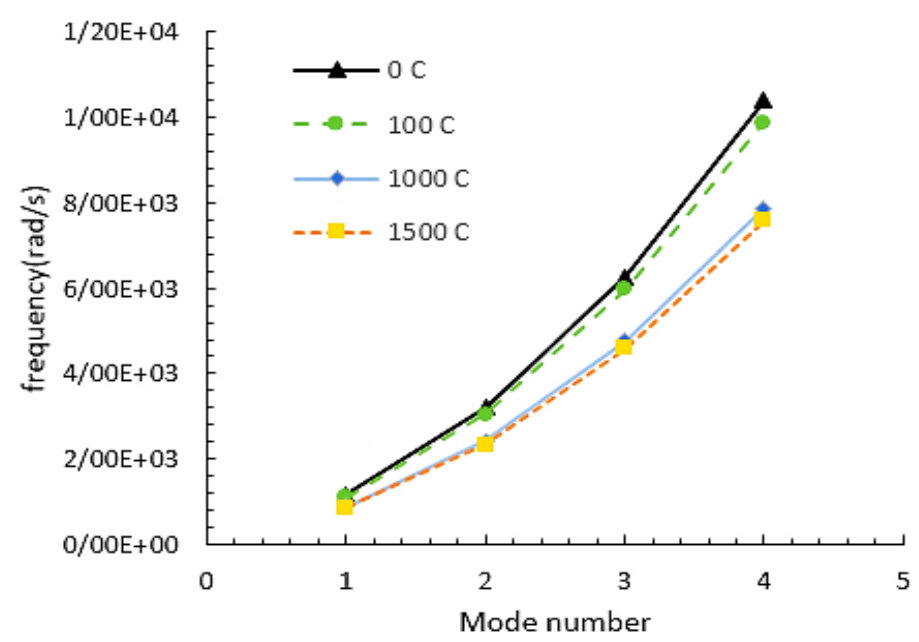

Fig. 13: Changes in natural frequencies by changing the temperature of the initial thermal field 
Rahmani et al., J. Mod. Sim. Mater.; Vol. 3 Issue 1, pp: 22-36, 2020

In Figure 14 it is seen that the existence of a mild initial field (up to 100 degrees) does not have much effect on the dynamic response but will reduce the natural shell frequencies (especially higher frequencies). However, the thermal field does not have a significant effect on the dynamic response in the short time, but after a while it reduces the hardness matrix values and will reduce the frequency and increase the range of displacement.

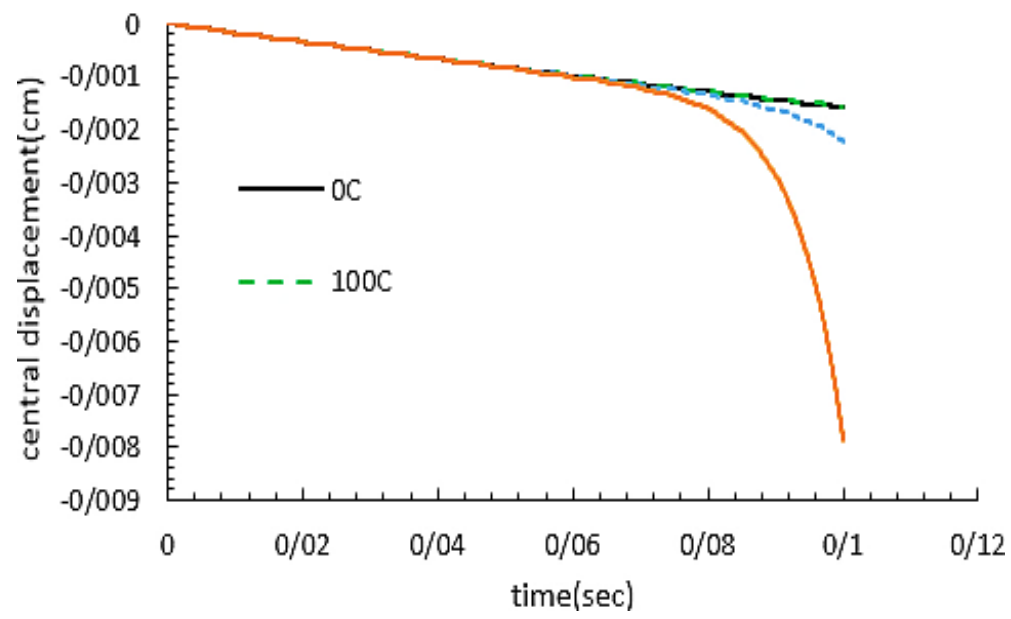

Fig. 14: Changes in the radial displacement of the intermediate layer with a change in Thermal field Boundary conditions are clamped as default. You can see the effect of other boundary conditions on the fundamental frequency of the shell in Figure 15.

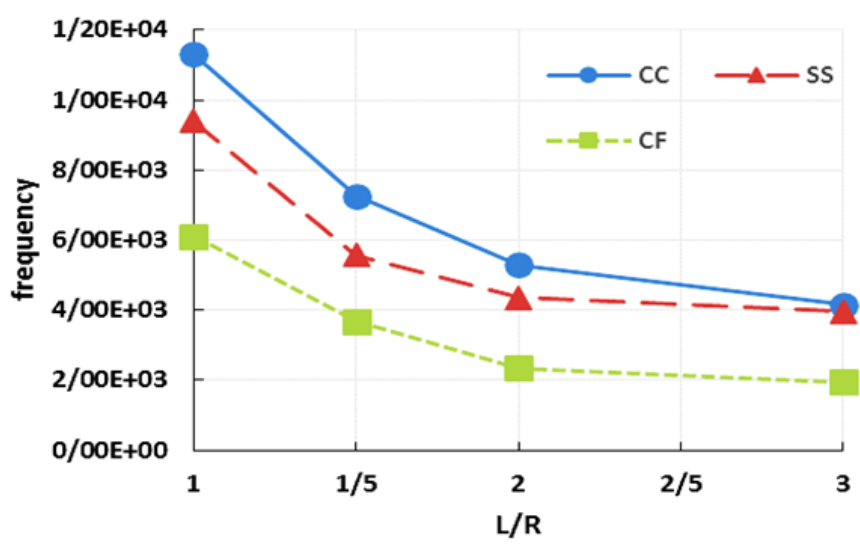

Fig. 15: Variation of the fundamental frequency parameter with Ratio of length to radius for different boundary conditions

The volume percentage of carbon nanotubes is another important parameter of this study, which is its effect on the fundamental frequency in Figure 16. increasing the volume ratio of carbon nanotubes increases the natural frequency of the cylindrical shell

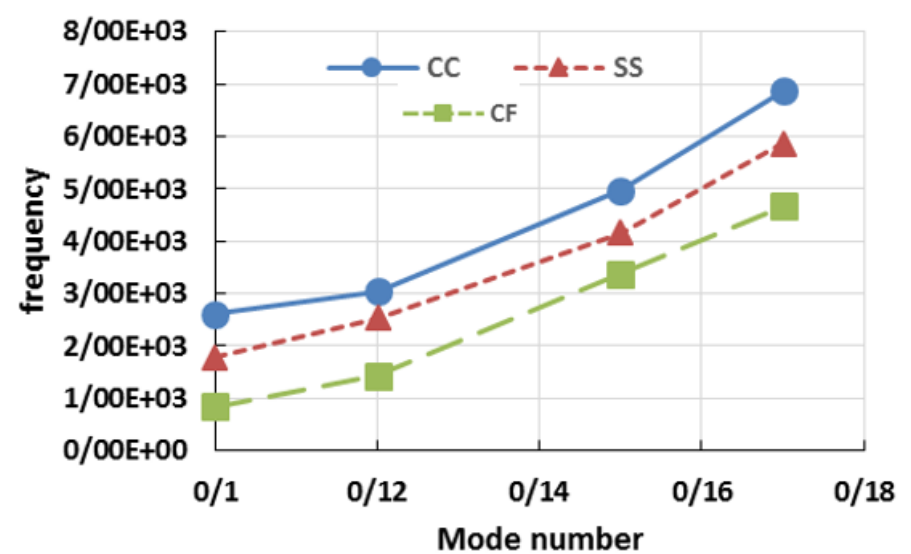

Fig. 16: Variation of the fundamental frequency parameter with the CNT volume fraction 


\section{Conclusions}

In this paper, the dynamics and vibrational responses of cylindrical shells of thin-walled composite materials under the primary thermal field and thermal shock were investigated. The influence of parameters such as radius, cylindrical length, shell thickness, temperature of the field and on the range of radial displacement of the middle layer and Natural frequencies were dealt with. Increasing the volume ratio of carbon nanotubes increases the natural frequency of the cylindrical shell. As the temperature increases, the natural frequency of the sheet decreases.By examining the effects of the heat field and thermal shock, it was found that a mild heat field (far away from the melting point of the composite matrix) does not have an effect on the dynamic response but reduces the natural frequency, especially higher frequencies. But the effect of increasing the thermal shock on the increase in displacement is considerable, but with transient effects it has no effect on natural frequencies.

\section{Competing Interests}

The authors declared that no conflict of interest exist in this publication.

\section{How to Cite this Article:}

M. Rahmani and A. Moslemi Petrudi, "Analytical Investigation of the Vibrational and Dynamic Response of Nano-Composite Cylindrical Shell Under Thermal Shock and Mild Heat Field by DQM Method”, J. Mod. Sim. Mater., vol. 3, no. 1, pp. 22-36, Mar. 2020. doi: 10.21467/jmsm.3.1.22-36

\section{Appendix}

$$
\begin{aligned}
& \mathrm{R}_{\mathrm{kz}}^{(1)}=\sum_{\mathrm{i}=1}^{\mathrm{N}} \mathrm{k}_{\mathrm{zz}}^{\mathrm{i}}\left(\mathrm{h}_{\mathrm{i}}-\mathrm{h}_{\mathrm{i}-1}\right) \text {, } \\
& R_{k z}^{(2)}=\sum_{i=1}^{N} \int_{h_{j-1}}^{h_{j}} k_{z z}^{j} z d z, \\
& \mathrm{R}_{\mathrm{kx}}^{(\mathrm{i})}=\sum_{\mathrm{i}=1}^{\mathrm{N}} \int_{\mathrm{h}_{\mathrm{j}-1}}^{\mathrm{h}_{\mathrm{j}}} \mathrm{k}_{\mathrm{xx}}^{\mathrm{j}} \mathrm{z}^{(\mathrm{i}-1)} \mathrm{dz} \quad \mathrm{i}=1,2,3 \\
& \mathrm{R}_{\mathrm{c}}^{(\mathrm{i})}=\sum_{\mathrm{i}=1}^{\mathrm{N}} \int_{\mathrm{h}_{\mathrm{j}-1}}^{\mathrm{h}_{\mathrm{j}}}<\rho \mathrm{c}_{\mathrm{v}}>_{\mathrm{j}} \mathrm{z}^{(\mathrm{i}-1)} \mathrm{dz} \quad \mathrm{i}=1,2,3 \\
& \mathrm{R}_{\mathrm{x}}^{(\mathrm{i})}=\sum_{\mathrm{i}=1}^{\mathrm{N}} \int_{\mathrm{h}_{\mathrm{j}-1}}^{\mathrm{h}_{\mathrm{j}}}<\mathrm{T}_{\mathrm{a}} \beta_{\mathrm{xx}}>_{\mathrm{j}} \mathrm{z}^{(\mathrm{i}-1)} \mathrm{dz} \quad \mathrm{i}=1,2,3 \\
& \mathrm{R}_{\theta}^{(\mathrm{i})}=\sum_{\mathrm{i}=1}^{\mathrm{N}} \int_{\mathrm{h}_{\mathrm{j}-1}}^{\mathrm{h}_{\mathrm{j}}}<\mathrm{T}_{\mathrm{a}} \beta_{\theta \theta}>_{\mathrm{j}} \mathrm{z}^{(\mathrm{i}-1)} \mathrm{dz} \quad \mathrm{i}=1,2,3 \\
& \mathrm{R}_{\mathrm{z}}^{(\mathrm{i})}=\sum_{\mathrm{i}=1}^{\mathrm{N}} \int_{\mathrm{h}_{\mathrm{j}-1}}^{\mathrm{h}_{\mathrm{j}}}<\mathrm{T}_{\mathrm{a}} \beta_{\mathrm{zz}}>_{\mathrm{j}} \mathrm{z}^{(\mathrm{i}-1)} \mathrm{dz} \quad \mathrm{i}=1,2,3 \\
& \mathrm{R}_{\mathrm{x} \theta}^{(\mathrm{i})}=\sum_{\mathrm{i}=1}^{\mathrm{N}} \int_{\mathrm{h}_{\mathrm{j}-1}}^{\mathrm{h}_{\mathrm{j}}}<\mathrm{T}_{\mathrm{a}} \beta_{\mathrm{x} \theta}>_{\mathrm{j}} \mathrm{z}^{(\mathrm{i}-1)} \mathrm{dz} \quad \mathrm{i}=1,2,3
\end{aligned}
$$




\section{References}

[1] McQuillen, E. J., Brull, M. A., Dynamic thermoelastic response of cylindrical shells, Journal of applied Mechanics 37(3): 661-670, 1970.

[2] M.R. Eslami, H. Vahedi, a general finite element stress formulation of dynamic thermoelastic problems using Galerkin method, J. Therm. Stresses 14 (1991) (in Persian).

[3] M.R. Eslami, M. Shakeri, R. Sedaghati, Coupled thermoelasticity of axially symmetric cylindrical shell, J. Therm. Stresses 17 (1), 115135, 1994(in Persian).

[4] M.R. Eslami, M. Shakeri, A.R. Ohadi, B. Shiari, coupled thermoelasticity of shells, effect of normal stress and coupling, AIAA J. 37 (4), 496-504, 1999 (in Persian).

[5] Hakimelahi, B., Soltani, N., A solution for the coupled dynamic thermoelastic problems of thin cylindrical shells under pressure shear and temperature shocks using finite element methods, J. Fac. Eng. Univ. Tehran 33 (3): 73-86, 1999 (in Persian).

[6] Eslami, M. R., Mousavi, S. M., Dynamic analysis of conical shells under mechanical and thermal loading by Galerkin finite element method, in: Second Conference of Aerospace Engineering in Iran: 535-543, 1998 (in Persian).

[7] Tarn, J. Q., Exact solutions for functionally graded anisotropic cylinders subjected to thermal and mechanical loads, International Journal of Solids and Structures 38(46-47): 8189-8206, 2001.

[8] Alibeigloo, A., Thermoelastic solution for static deformations of functionally graded cylindrical shell bonded to thin piezoelectric layers, Composite Structures 93(2): 961-972, 2011(in Persian).

[9] Ansari, R., Torabi, J., Faghih Shojaei, M., Free vibration analysis of embedded functionally graded carbon nanotube-reinforced composite conical/cylindrical shells and annular plates using a numerical approach. Journal of Vibration and Control, 24 (6): 1123-1144, 2016 (in Persian).

[10] Alibeigloo, A., Elasticity solution of functionally graded carbon nanotube-reinforced composite cylindrical panel subjected to thermo mechanical load, Composites Part B: Engineering 87: 214-226, 2016 (in Persian).

[11] Wang, Y. Z., et al. "Thermoelastic interaction in functionally graded thick hollow cylinder with temperature-dependent properties." Journal of Thermal Stresses 41.4, 399-417, 2018.

[12] Esmaeili H.R., Arvin H., Kiani Y., Axisymmetric nonlinear rapid heating of FGM cylindrical shells, Journal of Thermal Stresses 42(4): 490-505, 2019 (in Persian)

[13] Keibolahi A., Kiani Y., Eslami M.R., Dynamic snap-through of shallow arches under thermal shock, Aerospace Science and Technology 77: 545-554, 2018 (in Persian).

[14] Javani M., Kiani Y., Eslami M.R., Geometrically nonlinear rapid surface heating of temperature-dependent FGM arches, Aerospace Science and Technology 90: 264-274, 2019 (in Persian).

[15] Javani M., Kiani Y., Eslami M.R., Large amplitude thermally induced vibrations of temperature dependent annular FGM plates, Composites Part B: Engineering 163: 371-383, 2019 (in Persian).

[16] S.A.Mousavi., M. Rahmani, M. Kaffash Mirzarahimi, and S. Mahjoub Moghadas. "The Dynamic and Vibration Response of Composite Cylindrical Shell Under Thermal Shock and Mild Heat Field." Journal of Solid Mechanics, 2020 (in Persian).

[17] P. Zhu, Z.X. Lei, K.M. Liew, Static and free vibration analyses of carbon nanotube-reinforced composite plates using finite element method with first order shear deformation plate theory, Composite Structures,450-1460, 2012.

[18] Chang, J. S., Shyong, J. W., Thermally induced vibration of laminated circular cylindrical shell panels, Composites science and technology 51(3): 419-427, 1994.

[19] Bert, C. W., Kumar, M., Vibration of cylindrical shells of bimodulus composite materials, Journal of Sound and Vibration 81(1):107$121,1982$.

[20] Eslami, M., Vahedi, H., Galerkin finite element displacement formulation of coupled thermoelasticity spherical problems. Journal of pressure vessel technology 114(3): 380-384, 1992 (in Persian).

[21] Shiari, B., Eslami, M. R., Shaker, M., Thermomechanical shocks in composite cylindrical shells: a coupled thermoelastic finite element analysis. Scientia Iranica 10(1): 13-22, 2003 (in Persian).

[22] A. Ghorbanpour Arani, V. Atabakhshian, A. Loghman, A.R. Shajari, S. Amir, Nonlinear vibration of embedded SWBNNTs based on nonlocal Timoshenko beam theory using DQ method, Phisy. 2549-2555, 2012 (in Persian).

[23] T. Murmu, S.C. Pradhan, buckling analysis of a single-walled carbon nanotube embedded in an elastic medium based on nonlocal elasticity and Timoshenko beam theory and using DQM, Phisy. E 41,1232-1239, 2009.

[24] O. Civalek, Harmonic differential quadrature-finite differences coupled approaches for geometrically nonlinear static and dynamic analysis of rectangular plates on elastic foundation, J. Sound. Vib. 294, 966-980, 2006.

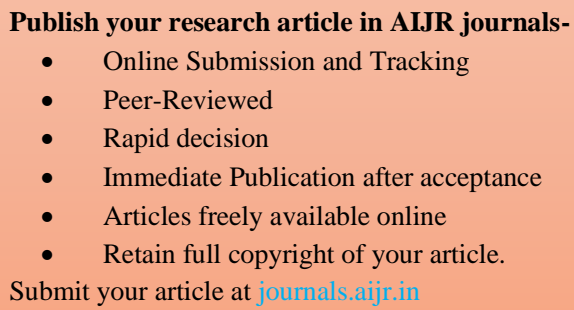

Publish your books with AIJR publisher-

- $\quad$ Publish with ISBN and DOI.

- Publish Thesis/Dissertation as a Book.

- Publish Monograph.

- Publish Edited Volume/ Book.

- Publish Conference Proceedings

- Retain full copyright of your books.

Submit your manuscript at books.aijr.org 